\title{
Paraphoma Crown Rot of Pyrethrum (Tanacetum cinerariifolium)
}

Azin Moslemi, Faculty of Veterinary and Agricultural Science, University of Melbourne, VIC, 3010, Australia; Peter K. Ades, Department of Forest and Ecosystem Science, University of Melbourne, VIC, 3010, Australia; Tim Groom, Botanical Resources Australia Pty Ltd, Ulverstone, Tasmania; Pedro W. Crous, Faculty of Veterinary and Agricultural Science, University of Melbourne; and CBS-KNAW Fungal Biodiversity Centre, Utrecht, The Netherlands; and Marc E. Nicolas and Paul W. J. Taylor, Faculty of Veterinary and Agricultural Science, University of Melbourne

\begin{abstract}
Moslemi, A., Ades, P. K., Groom, T., Crous, P. W., Nicolas, M. E., and Taylor, P. W. J. 2016. Paraphoma crown rot of pyrethrum (Tanacetum cinerariifolium). Plant Dis. 100:2363-2369.

Pyrethrum (Tanacetum cinerariifolium) is commercially cultivated for the extraction of natural pyrethrin insecticides from the oil glands inside seed. Yield decline has caused significant yield losses in Tasmania during the last decade. A new pathogen of pyrethrum causing crown rot and reduced growth of the plants in yield decline affected fields of northern Tasmania was isolated from necrotic crown tissue and described as Paraphoma vinacea. Multigene phylogenetic identification of the pathogen also revealed that $P$. vinacea was a new species different from other Paraphoma type strains. Glasshouse

pathogenicity experiments showed that $P$. vinacea significantly reduced belowground and total biomass of pyrethrum plants 2 months after inoculation. Dull-tan to reddish-brown discoloration of the cortical and subcortical crown tissue was observed in $100 \%$ of the infected plants. P. vinacea infected $75 \%$ of the plants inoculated with root dip and soil drench inoculation techniques in an inoculation optimization experiment. $P$. vinacea, the causal agent of Paraphoma crown rot disease, represents an important pathogen that will negatively impact the commercial cultivation of pyrethrum in Tasmania.
\end{abstract}

Pyrethrum (Tanacetum cinerariifolium (Trevir.) Schultz-Bip.) is a perennial plant cultivated commercially for the extraction of natural pyrethrin insecticides. In Australia, commercial pyrethrum production occurs in Tasmania and Victoria, which satisfies the majority of the global demand of natural pyrethrins (Hay et al. 2015).

Fields are planted with pyrethrum seed in winter (July to September), with first harvest occurring in spring (December) and January of the following year (15 to 17 months after planting). Thereafter, crops are harvested annually at the same time of year. Every spring, plants produce multiple stems in response to increasing day length, reaching the maximum height of approximately 1 to $1.5 \mathrm{~m}$ within 12 weeks (Pethybridge et al. 2008). Ideally, under this intensive production system, pyrethrum fields should remain productive for at least four harvests. However, when pyrethrum yield decline occurs, some patches of plants in pyrethrum fields are not able to regrow effectively after harvest (Hay et al. 2002). In some cases, crops which had produced a reasonable yield in the previous season were affected by the yield-decline syndrome (Hay et al. 2002). In the last decade, yield decline has increased in both Tasmania and Victoria, believed to be due to a combination of biotic and abiotic factors.

In 2014, a new disease of pyrethrum causing severe necrosis and chlorosis of the crown tissue in plants growing in yield decline affected fields of northern Tasmania was identified and a Paraphoma sp. was consistently isolated from the necrotic crown tissue. Previously, Paraphoma chrysanthemicola was reported as a foliar pathogen isolated from necrotic leaf lesions of young plants along with other important foliar pathogens of pyrethrum such as Colletotrichum tanaceti, Didymella tanaceti, and Stagonosporopsis tanaceti (Barimani et al. 2013; Pearce et al. 2016; Vaghefi et al. 2012). Hay et al. (2015) identified P. chrysanthemicola based on morphological

Corresponding author: P. W. J. Taylor; E-mail: paulwjt@unimelb.edu.au

Accepted for publication 28 July 2016.

http://dx.doi.org/10.1094/PDIS-05-16-0628-RE

(C) 2016 The American Phytopathological Society characteristics, according to Garibaldi and Gullino (1981). However, most species of Paraphoma have been reported to be soilborne pathogens associated with the diseases of monocotyledonous plants (families Gramineae, Iridaceae, and Liliaceae) (Boerema et al. 2004; de Gruyter and Boerema 2002). P. chrysanthemicola (syn. Phoma chrysanthemicola) was first described by Hollós in 1907 (de Gruyter et al. 2010). Later, Srivastava (1953) reported a Phoma-like pathogen at the base of the flower stems of Chrysanthemum spp. and identified it as P. chrysanthemicola. Paraphoma chrysanthemicola was also isolated from the roots of Chrysanthemum morifolium in Germany in 1967 (de Gruyter et al. 2010). Later, Dorenbosch (1970) reported it as a pathogen involved with the root disease of florists' chrysanthemum. Johnston (1981) also reported it as root pathogen of Leguminosae spp. such as Medicago sativa, causing damping-off and root rot. Therefore, identification of Paraphoma isolates associated with pyrethrum crown rot disease needs to be undertaken using molecular and phylogenetic analyses to confirm its identification.

The genus Paraphoma is related to Phoma, a cosmopolitan group of fungi which include primary and secondary pathogens of agricultural crops around the world. Paraphoma spp. are known to have various lifestyles, from endophytes colonizing plants without producing symptoms to pathogens infecting different plant organs causing disease (Roustaee et al. 2000). In the pathogenic species, primary infection usually occurs through wounds caused by mechanical activities in fields or by direct penetration through stomata (Aveskamp et al. 2008). Aveskamp et al. (2008) presented a common life cycle for all phytopathogenic Phoma spp., including Paraphoma, regardless of the differences in their ecological niches. Fungal mycelium grows inside the plant tissue before producing toxins that cause cell death and necrosis (Hammond and Lewis 1987). Black pycnidia produced on dead plant tissues are sources of conidia which can easily be dispersed by water splash, wind, and birds (Aveskamp et al. 2008). These pathogens have also been reported as soilborne pathogens associated with root diseases in temperate areas of Australia, America, and Eurasia (de Gruyter et al. 2010).

The aims of this article were to (i) identify and describe the Paraphoma sp. causing crown rot disease in pyrethrum plants in northern Tasmania, (ii) develop a glasshouse bioassay to reproduce 
Paraphoma crown rot disease of pyrethrum, and (iii) determine the effect of the Paraphoma sp. on growth of pyrethrum plants.

\section{Materials and Methods}

Sample collection. In June 2014, nine pyrethrum plants showing poor regrowth after harvest were sampled from nine yield decline affected fields in northern Tasmania (one plant per field). Plants from each site exhibited stunted growth and necrotic crown tissue. In January 2015 , pyrethrum plants with poor regrowth were again sampled from three of the nine yield-decline-affected sites (seven plants each site) which had managed to regrow after harvest.

Isolation of Paraphoma sp. Plant roots were washed gently in tap water for $5 \mathrm{~min}$ to remove excess soil. Tissues from the upper primary roots, crowns, petioles, and leaves were sectioned (0.5- to $1-\mathrm{cm}$ pieces) and immersed in $80 \%$ ethanol for $30 \mathrm{~s}$, before transferring to $1 \%$ (active ingredient) sodium hypochlorite for $1 \mathrm{~min}$, followed by rinsing in sterilized water. Samples were subsequently blotted on a sterilized paper towel and cultured on $2 \%$ water agar (WA). Plates were incubated under white fluorescent light at 23 to $25^{\circ} \mathrm{C}$ for 3 to 4 days. Emerging hyphal growth was subcultured onto oatmeal agar (OA) (Crous et al. 2009) and incubated according to the conditions described by Boerema et al. (2004).

Phoma-like strains (UMPv001, UMPv002, UMPv003, and UMPv004) which were recovered from different tissues (including mostly the upper primary roots and crown and, at a lower frequency, from the base of the petioles of the yield decline affected plants from the 2014 survey) were taxonomically characterized. A culture of the strains was deposited at the Queensland Plant Pathology Herbarium (BRIP), Brisbane, Australia.

In the 2015 survey, strains were recovered from the upper primary roots and crown of the sampled plants from three sites, with UMPv005 being used to assess pathogenicity and effect on growth.

Morphological characterization. Subcultures of each strain were made onto OA, malt extract agar (MEA), and cherry decoction agar (CHA) (Crous et al. 2009) to measure colony growth rate after 7 days of incubation at 22 to $24^{\circ} \mathrm{C}$ in darkness (Boerema et al. 2004); colony color was assessed after 2 weeks using Rayner's color chart (Rayner and British Mycological Society 1970). Conidia, chlamydospores, and pycnidia were mounted in lactic acid and measurements of 30 replicates of each structure were made using a Leica DM-2900 compound microscope. Conidial dimensions were measured on OA, MEA, and CHA (Aveskamp et al. 2010), while other structures were measured from the colonies sporulating on OA. Chlamydospore shape was also recorded in cultures growing on OA.

For microtome sectioning, cultures were also grown on sterilized pyrethrum flower stems $\left(5-\mathrm{cm}\right.$ pieces autoclaved twice at $121^{\circ} \mathrm{C}$ for $20 \mathrm{~min}$ ) by placing the stems on WA and then placing $5-\mathrm{mm}^{2}$ agar blocks of mycelium next to the stems and incubating at 22 to $24^{\circ} \mathrm{C}$ in darkness. Once the stems were colonized, pycnidia that developed after 2 weeks were measured and photographed. Individual pycnidia were lifted from the WA medium using a sterilized needle (dipped in $80 \%$ ethanol and flamed) and placed into formaldehyde acetic acid for 2 days. Samples were dehydrated in tertiary butyl alcohol (TBA) at increasing concentrations $(20,40,60$, and $80 \%$ and three times in $100 \%)$ for $10 \mathrm{~min}$ at each concentration. They were then immersed in TBA and xylene (1:1) solution and incubated at room temperature for $2 \mathrm{~h}$. Samples were immersed in $100 \%$ xylene for another $2 \mathrm{~h}$ at room temperature. Xylene was used as clearing agent and made the samples more translucent. Thereafter, samples were left in a mixture of $50 \%$ paraffin- $50 \%$ xylene water bath at 55 to $60^{\circ} \mathrm{C}$ overnight. The day after, $50 \%$ paraffin was replaced with $100 \%$ paraffin and left for another 2 days in a water bath at $60^{\circ} \mathrm{C}$. Pycnidia were sectioned using a Leica RM2125 RTS microtome, with 7- $\mu \mathrm{m}$ thick sections mounted in lactic acid on glass microscope slides.

Physiological diagnosis tests were carried out to identify color changes in cultures and pycnidia. A drop of $1 \mathrm{~N} \mathrm{NaOH}$ was applied to the mycelium at the growing margin of the culture to determine the production of metabolite "E;" and to determine the type of pycnidial cell wall, a drop of iodine was applied to pycnidia placed on a glass microscope slide and then squashed (Boerema et al. 2004) (Phoma methodologies http://www.q-bank.eu).

Molecular characterization. DNA extraction and PCR amplification. Total genomic DNA of isolates UMPv001, UMPv002, UMPv003, and UMPv004 was extracted from fungal mycelium scraped directly from 7-day-old single-spored cultures grown on OA. Extraction was done using the DNeasy Plant Mini Kit (Qiagen Pty. Ltd.) following the manufacturer's instructions. Internal transcribed spacer (ITS), $\beta$-tubulin $(T U B)$, and actin $(A C T)$ loci were amplified using V9G (de Hoog and Gerrits van den Ende 1998) and ITS4 (White et al. 1990), TUB2Fd and TUB4Rd (Woudenberg et al. 2009), and ACT 512F and ACT 738R (Carbone and Kohn 1999) primer pairs, respectively. Elongation factor 1- $\alpha$ (tefl) was amplified using EF1-728F (Carbone and Kohn 1999) and EF2 (O’Donnell et al. 1998). The large subunit (LSU) region was amplified with the primers LR0R (Rehner and Samuel 1994) and LR7 (Vilgalys and Hester 1990). The same set of primers was used for sequencing of each gene, with the exception of LSU, in which LR5 (White et al. 1990), an additional primer, was used as an internal primer in order to ensure that the whole region was sequenced. All PCR amplifications were performed in a Bio-Rad Australia Ltd. thermal cycler, with a total reaction volume of $12.5 \mu$ l. The PCR conditions for ITS, $T U B$, and $A C T$ were as described by Aveskamp et al. (2009), except for $A C T$, in which the annealing temperature was increased to $60^{\circ} \mathrm{C}$. LSU and tef1 PCR amplifications were performed according to Quaedvlieg et al. (2013). PCR products were then purified using a QIAquick PCR purification kit (Qiagen Pty. Ltd.) following the manufacturer's instructions.

Sequencing and multigene analysis. Purified amplicons were submitted to the Australian Genome Research Facility Ltd. for sequencing. Consensus sequences were obtained from both forward and reverse sequences using the sequence alignment editing program Clustal W within the Geneious v.7.0.6 software (Kearse et al. 2012). All sequences were submitted to GenBank and accession numbers were obtained. BLAST searches for LSU, ITS, TUB, $A C T$, and tefl sequences were conducted in the National Centre for Biotechnology Information (nr) database within GenBank. Related sequences of Paraphoma spp. showing high similarity to the pyrethrum strains were downloaded from GenBank (Table 1).

Phylogenetic analysis. Maximum-likelihood (ML) and neighborjoining $(\mathrm{NJ})$ phylogenetic trees were constructed for each gene individually and combined using MEGA6 (Tamura et al. 2013) for ML and "Geneious tree builder" for NJ analyses within Geneious (Biomatters Ltd.). Three different combined phylogenetic trees were constructed. The best-fit substitution models for ML analyses were determined using MEGA6. Gaps were treated as missing data. For the NJ analyses, HKY substitution model and pairwise deletion of the gaps were utilized. To assess the relative stability of branches, bootstrap analysis with 1,000 pseudoreplicates was performed for both analyses.

The combined tree of LSU and ITS was used for species of closely related genera to assess the placement of the isolates within the family Phaeosphaeriaceae (Quaedvlieg et al. 2013). The ACT sequences were not available for every Paraphoma sp. in the reference publications; hence, two separate phylogenetic analyses were undertaken: ITS, $T U B$, and tefl sequences and ITS, $T U B$, and $A C T$ sequences. Individual and combined phylogenetic trees were deposited in TreeBASE at www.treebase.org/treebase-web/home.html.

Pathogenicity tests. Inoculation optimization. Three inoculation methods of root dip, foliar spray, and soil drench were assessed to determine the most appropriate inoculation method for reproducing the disease in the glasshouse and for assessing pathogenicity in pyrethrum plants.

Pyrethrum seedlings were germinated from steam-sterilized seed and raised in a seedling mix in Tasmania. Seedlings were then sent to the University of Melbourne in June 2014 and transferred to 10 -cm-diameter pots with potting mix and fertilized with $5 \mathrm{~g}$ of Osmocote (Scotts Australia Pty. Ltd.) per pot fortnightly. Seedlings were then left in a glasshouse for 2 months to establish. A completely randomized design was used for this experiment, inoculating eight replicates of 3-month-old 'Pyrate' pyrethrum plants with Paraphoma strain UMPv001 at a spore suspension of $10^{5}$ spore $/ \mathrm{ml}$. Eight replicates of controls were also inoculated with sterilized water in each inoculation method.

In the root dip method, each 3-month-old pyrethrum plant was removed from soil in pots, washed in running tap water, then immersed into $200 \mathrm{ml}$ of the spore suspension for $10 \mathrm{~min}$; each plant was subsequently replanted into the same pot $(10 \mathrm{~cm}$ in diameter). For foliar 
inoculation, a Jet-Pak hand sprayer (Wattyl Pty. Ltd. Australia) was used to spray the leaves of plants with the spore suspension until just before run-off; then, each plant was covered with a plastic bag for $24 \mathrm{~h}$ to increase humidity and enhance spore germination. In the soil drench method, $50 \mathrm{ml}$ of spore suspension was poured around the crown and subcrown areas of each pyrethrum seedling. Plants were maintained in the glasshouse, watered by drip irrigation, and fertilized with $5 \mathrm{~g}$ of Osmocote (Scotts Australia Pty. Ltd.) once per month. Two months after inoculation, plants were carefully removed from the soil and approximately $5 \mathrm{~mm}$ of tissue each from the crown, upper primary roots, leaf, and petiole of each plant was surfaced sterilized, sectioned, and cultured on WA, as previously described. Mycelia that grew from the tissues were subcultured onto potato dextrose agar and then onto OA for morphological characterization. Tissue from control plants was also cultured similarly to the inoculated plants. After sampling and culture, the remaining parts of the plants were divided into leaves and petioles (aboveground); and crown and root (belowground) for each sample, then dried in an oven for 3 days at $71^{\circ} \mathrm{C}$ and weighed.

Pathogenicity and effect of $\mathrm{P}$. vinacea on growth of pyrethrum plants. Two glasshouse experiments were undertaken to determine the effect of $P$. vinacea on pyrethrum growth. In experiments 1 and 2, 8 replicates of 2-month-old and 10 replicates of 3-monthold Pyrate pyrethrum plants, respectively, were root dip inoculated with a spore suspension of Paraphoma isolate UMPv005 at $10^{5}$ spore/ml, which was prepared from a single-spore culture grown on MEA, as described previously. Control plants were dipped in sterilized water. These experiments were planted at different times of the year: experiment 1 in winter and experiment 2 in summer. After 2 months, plants were harvested and tissues from the upper primary roots, crown, base of petioles, and leaf were surface sterilized and cultured as described. Plant biomass from above and below the soil level and total biomass were measured in both experiments.

Analysis of the dry weights was examined by a one-way analysis of variance experimental design using the SAS computer package. Data were transformed using the logarithmic transformation method.

\section{Results}

Isolate identification. Morphological characterization and phylogenetic analysis suggested that the Paraphoma sp. isolated from necrotic crown and upper primary root tissue from pyrethrum plants growing in yield decline affected sites was a new species, for which the name Paraphoma vinacea has been proposed.

Paraphoma vinacea. A Moslemi, PWJ Taylor, sp. nov.

MycoBank: MB 815348

Etymology: Named after the vinaceous red color which it produces on MEA, CHA, and OA agar media.

Morphological and cultural characteristics. On OA. Colony diameter $15 \mathrm{~mm}$ after 1 week; aerial mycelium floccose, white grayish. Colony pigmentation after 2 weeks olivaceous gray at the margin and dark vinaceous in the center. Reverse similar. Margins regular or slightly regular.

Conidiomata pycnidial, ostiolate, unilocular and solitary, submerged in agar, obpyriform, semi-pilose, pale to dark brown; 250 to $500 \mu \mathrm{m}$ diameter. Conidial matrix cream colored; pycnidial cell wall 10 to $15 \mu \mathrm{m}$ thick, micropycnidia abundant and submerged in the medium, pale brown. Conidiophores reduced to phialidic conidiogenous cells, hyaline, smooth and ampulliform, 3.5 to $4.1 \mu \mathrm{m}$ length. Conidia aseptate, ellipsoid to oblong, 2 to 4.5 (SD 0.4) $\times 4$ to 7 (SD 0.58) $\mu \mathrm{m}$. Chlamydospores abundant, occurring in long chains or aggregated,

Table 1. Collection details and GenBank accession numbers of isolates

\begin{tabular}{|c|c|c|c|c|c|c|c|c|}
\hline \multirow[b]{2}{*}{ Isolates } & \multirow[b]{2}{*}{ Collection $^{w}$} & \multirow[b]{2}{*}{ Substrata } & \multirow[b]{2}{*}{ Location } & \multicolumn{5}{|c|}{ GenBank accession number } \\
\hline & & & & LSU & ITS & TUB & tef1 & ACT \\
\hline$\overline{\text { Didymella americana }}$ & CBS 185.85 & Zea mays & United States & $\ldots$ & FJ426972x & FJ427088x & $\cdots$ & FJ426870 \\
\hline $\begin{array}{l}\text { Neosetophoma } \\
\text { samarorum }\end{array}$ & CBS 138.96 & Phlox paniculata & Netherlands & KF251664y & KF251160y & KF252655 & KF253119 y & $\ldots$ \\
\hline $\begin{array}{l}\text { Paraphoma } \\
\text { chrysanthemicola }\end{array}$ & CBS 522.66* & $\begin{array}{l}\text { Chrysanthemum } \\
\text { morifolium }\end{array}$ & United Kingdom & KF251670y & KF251166 & KF252661 & KF253124y & JN251989 \\
\hline P. chrysanthemicola & CBS 172.70 & C. morifolium & Netherlands & KF251669y & KF251165y & KF252660y & KF253123y & $\ldots$ \\
\hline P. dioscoreae & CBS $135100^{* *}$ & Dioscorea tokoro & South Korea & KF251671y & KF251167y & KF252662y & KF253125y & $\ldots$ \\
\hline P. dioscoreae & CPC 11355 & D. tokoro & South Korea & KF251672y & KF251168y & KF252663y & $\mathrm{KF} 253126^{\mathrm{y}}$ & $\ldots$ \\
\hline P. dioscoreae & CPC 11361 & D. tokoro & South Korea & KF251673y & KF251169y & KF252664y & KF253127y & $\ldots$ \\
\hline P. fimeti & CBS $170.70^{*}$ & Apium graveolens & Netherlands & KF251674y & KF251170y & KF252665y & KF253128y & $\ldots$ \\
\hline$P$. fimeti & CBS 368.91 & Juniperus communis & Switzerland & KF251675y & KF251171y & KF252666 & KF253129y & $\ldots$ \\
\hline P. radicina & CBS 102875 & $\begin{array}{c}\text { Lycopersicon } \\
\text { esculentum }\end{array}$ & Germany & $\mathrm{KF} 251671^{\mathrm{y}}$ & $\mathrm{KF} 251671^{\mathrm{y}}$ & $\mathrm{KF} 251671^{\mathrm{y}}$ & KF251671 & $\ldots$ \\
\hline P. radicina & CBS $111.79 * * *$ & Malus sylvestris & Netherlands & KF251676y & KF251172y & KF252667y & KF253130y & \\
\hline P. vinacea & $\begin{array}{l}\text { UMPv001; } \\
\text { BRIP 63684** }\end{array}$ & $\begin{array}{l}\text { Tanacetum } \\
\text { cinerariifolium }\end{array}$ & $\begin{array}{l}\text { Australia; } \\
\text { Tasmania }\end{array}$ & KU176888 & KU176884 & KU176892 & KU176896 & KU176900 \\
\hline P. vinacea & $\begin{array}{l}\text { UMPv002; } \\
\text { BRIP } 63683\end{array}$ & T. cinerariifolium & $\begin{array}{l}\text { Australia; } \\
\text { Tasmania }\end{array}$ & KU176889 & KU176885 & KU176893 & KU176897 & KU176901 \\
\hline P. vinacea & $\begin{array}{l}\text { UMPv003; } \\
\text { BRIP } 63682\end{array}$ & T. cinerariifolium & $\begin{array}{l}\text { Australia; } \\
\text { Tasmania }\end{array}$ & KU176890 & KU176886 & KU176894 & KU176898 & KU176902 \\
\hline P. vinacea & $\begin{array}{l}\text { UMPv004; } \\
\text { BRIP 63685 }\end{array}$ & T. cinerariifolium & $\begin{array}{l}\text { Australia; } \\
\text { Tasmania }\end{array}$ & KU176891 & KU176887 & KU176895 & KU176899 & KU176903 \\
\hline Phaeosphaeria alpina & CBS 456.84 & Phleum alpinum & Switzerland & KF251684y & KF251181y & KF252675y & KF253139y & $\ldots$ \\
\hline $\begin{array}{l}\text { Phaeosphaeria } \\
\text { typharum }\end{array}$ & CBS 296.54 & Nardus stricta & Switzerland & KF251695y & KF251192y & KF252686 & KF253148y & $\ldots$ \\
\hline Phoma herbarum & CBS 615.75 & Rosa multiflora & Netherlands & KF25171 & KF251212y & KF252703y & KF253168y & $\ldots$ \\
\hline $\begin{array}{l}\text { Xenoseptoria } \\
\text { neosaccardoi }\end{array}$ & CBS 120.43 & Cyclamen persicum & Netherlands & KF251783y & KF251280y & $\mathrm{KF} 252761^{\mathrm{y}}$ & KF253227y & $\ldots$ \\
\hline
\end{tabular}

${ }^{\text {w }}$ Strain or culture collection number; *indicates the isolate in the ex-neotype, $* *$ the ex-holotype, and *** the ex-epitype. CBS 135100 is the ex-holotype of

Paraphoma dioscoreae, CBS 170.70 is the ex-neotype of Paraphoma fimeti, and CBS 111.79 is the ex-epitype of Paraphoma radicina. BRIP $=$ Queensland

Plant Pathology herbarium; Brisbane, Australia; CBS = Centraalbureau voor Schimmelcultures, the Netherlands; CPC $=$ Culture collection of Pedro Crous,

housed at CBS; and UMPv = University of Melbourne, Paraphoma vinacea strain.

x Aveskamp et al. (2009).

y Quaedvlieg et al. (2013).

${ }^{z}$ de Gruyter et al. (2012). 
hyaline to pale brown, ellipsoid to globose and aseptate, $16 \mu \mathrm{m}$ diameter (Fig. 1).

Sexual morph not observed. On MEA. Colony diameter $15 \mathrm{~mm}$ after 1 week; aerial mycelia white grayish and effuse. Colony pigmentation after 2 weeks scarlet red at the margins, and dark red to black in the center, with concentric rings formed from the center toward the margin of the plate. Reverse, red at the margins and olivaceous gray toward the center. Margins regular. Conidia aseptate, ellipsoid to oblong, 2 to 4 (SD 0.35) $\times 4$ to 6.5 (SD 0.53) $\mu \mathrm{m}$.
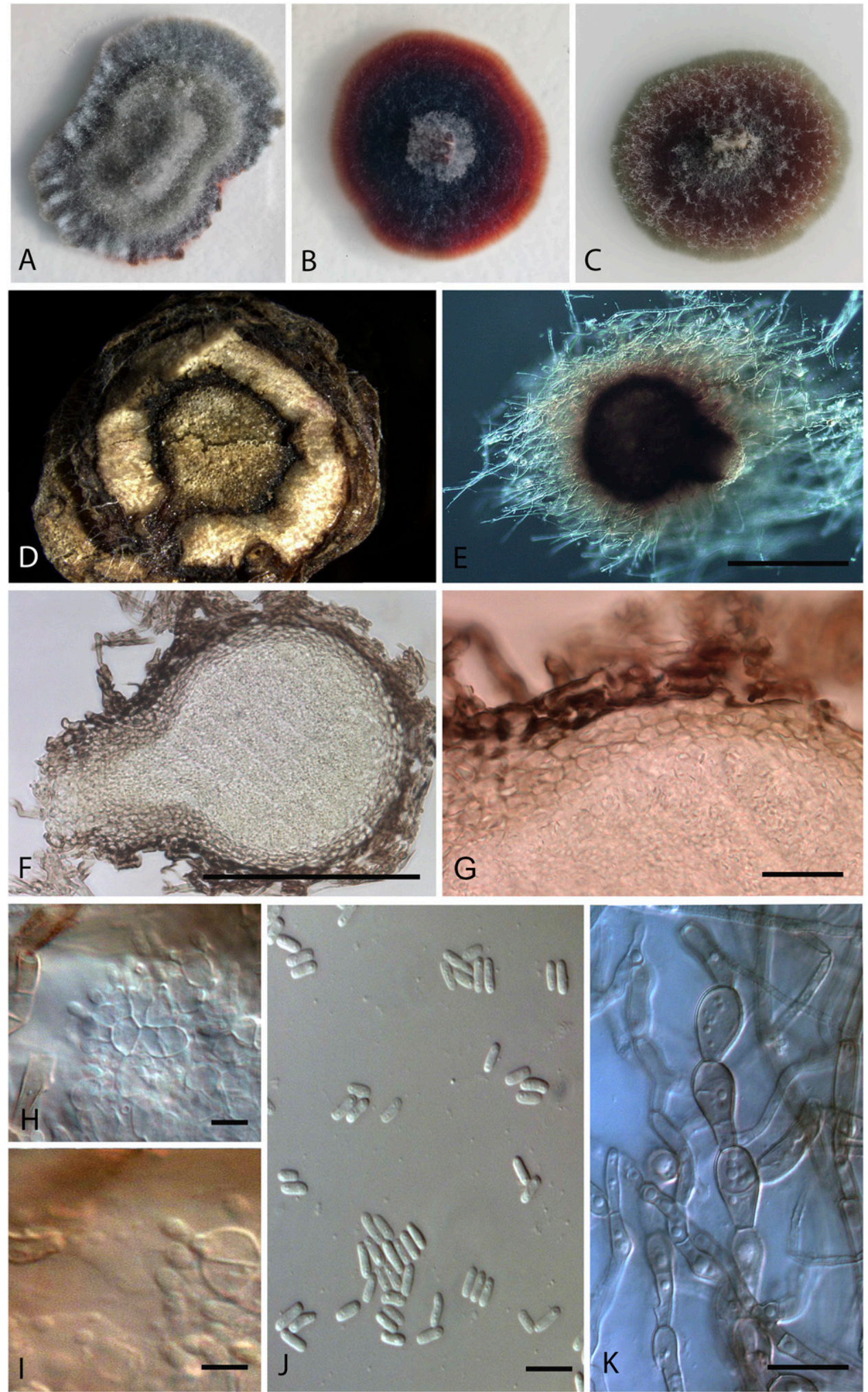

Fig. 1. Symptoms caused by Paraphoma vinacea: morphological and taxonomic characteristics. Colonies on A, cherry decoction agar; B, oatmeal agar (OA); and C, malt extract agar. D, Internal crown and subcrown necrosis of a pyrethrum plant infected with $P$. vinacea 2 months after inoculation. E, Flask-shaped and unilocular pycnidium on OA. F, Microtome cross-section (7- $\mu \mathrm{m}$ thickness) of a pycnidium. G, Pycnidial cell wall. $\mathbf{H}$ and $\mathbf{I}$, Conidiogenous cells. J, Oblong and hyaline conidia. $\mathbf{K}$, Chlamydospores in chains on OA. Scale bars: $\mathrm{E}=50 \mu \mathrm{m} ; \mathrm{F}, \mathrm{G}, \mathrm{J}$, and $\mathrm{K}=20 \mu \mathrm{m} ; \mathrm{H}$ and $\mathrm{I}=5 \mu \mathrm{m}$. 
On CHA. Colony diameter $20 \mathrm{~mm}$ after 1 week; aerial mycelium floccose, white to pale green. Colony pigmentation after 2 weeks, dark olivaceous on both sides and dark vinaceous in the center of the reverse side. Margins thick and irregular. Conidia aseptate, ellipsoid to oblong, 2 to 3 (SD 0.22$) \times 3.5$ to $5.5(\mathrm{SD}$ 0.39) $\mu \mathrm{m}$.

Physiological characteristics. No change of color was observed upon application of $1 \mathrm{~N} \mathrm{NaOH}$ to mycelium growing on $\mathrm{OA}$; however, the red color of the colony faded $1 \mathrm{~h}$ after the application of $\mathrm{NaOH}$ (Boerema et al. 2004; Dorenbosch 1970). No change of color was observed upon application of iodine to squashed pycnidia on MEA; hence, the cell wall type was identified as pseudoparenchymatous (Phoma methodologies, http:// www.q-bank.eu).

Specimen examined. Holotype. Australia, northern Tasmania, Devonport, from Tanacetum cinerariifolium, June 2014, A. Moslemi (BRIP 63684), culture ex-holotype (UMPv001).

Notes. Differs from $P$. chrysanthemicola described by Boerema et al. (2004) (conidia (3.5-) 4-5.5 $(-6.5) \times 1.5-2(-2.5) \mu \mathrm{m})$ by larger conidia on MEA and OA and slower growth rate. $P$. chrysanthemicola produces yellow pigmentation on OA (Johnston 1981), which does not occur in cultures of $P$. vinacea.

Phylogenetic studies. Four strains of $P$. vinacea formed a wellsupported monophyletic clade, distinct from $P$. chrysanthemicola (CBS 522.55; ex-neotype) in tefl, ITS, TUB, and ACT individual phylogenetic trees, with bootstrap support of 98.9, 99.5, 84.6, and $96.4 \%$, respectively. In the LSU individual tree, however, $P$. vinacea clustered with the type cultures of $P$. radicina and $P$. chrysanthemicola (individual trees were not shown).

The best-fit model in the combined multilocus phylogeny of ITS/ LSU was $\mathrm{K} 2+\mathrm{G}+\mathrm{I}$, with the total of 1,228 (ITS/LSU = 475:753) positions in the final dataset, of which 228 sites were variable (ITS/LSU = 183:45). In the tree of ITS/LSU, the four strains clustered separately in section Paraphoma close to P. chrysanthemicola (Fig. 2). The best-fit model for the combined ML tree of ITS/TUB/tefl and ITS/ACT/TUB (data not shown) was $\mathrm{K} 2+\mathrm{G}$. In the combined ITS/TUB/tef1, 888 (ITS/TUB/tef1 = 442:273:173) positions, in total, in the final dataset were obtained, of which 283 (ITS/TUB/tef1 = 136:88:59) were variable. The four strains of $P$. vinacea clustered together and formed a clade separate from $P$. chrysanthemicola, with high bootstrap support of $99 \%$ in the combined ML phylogenetic tree of ITS, tefl, and TUB (Fig. 3). In the combined ML tree of $A C T / \mathrm{ITS} / T U B$, in total, 907 (ACT/ ITS $/ T U B=184: 395: 328)$ positions in the final data set were obtained, with 253 variable sites $(A C T / \mathrm{ITS} / T U B=62: 100: 91)$. A combined ML phylogenetic tree of ITS, $A C T$, and $T U B$ also showed that the four strains of $P$. vinacea formed a clade separate from $P$. chrysanthemicola, with a bootstrap value of $98 \%$ (tree not shown). NJ bootstrap values supported those obtained from ML analyses, with slight differences.

Pathogenicity tests. Inoculation optimization. P. vinacea (UMPv001) infected the crown and root tissue of six of the eight replicate plants in the root dip and soil drench treatments but the petiole and crown tissue of only four of eight of the plants in the foliar spraying treatment. No controls were infected.

Effect of $\mathrm{P}$. vinacea on growth of pyrethrum plants. In the first experiment, $P$. vinacea (UMPv005) infected the crown tissue and upper primary roots of seven and three plants, respectively, and was also isolated from the leaf of one plant. In the second experiment, $P$. vinacea (UMPv005) infected the crown tissue and upper primary roots of 6 and 8 of the 10 root-dip-inoculated plants, respectively. There were no obvious leaf necrotic lesions and no control plants were infected in both experiments.

In the first experiment, $P$. vinacea significantly decreased the belowground dry weight of infected plants but had no significant effect on the aboveground and total biomass of the plants. In the second

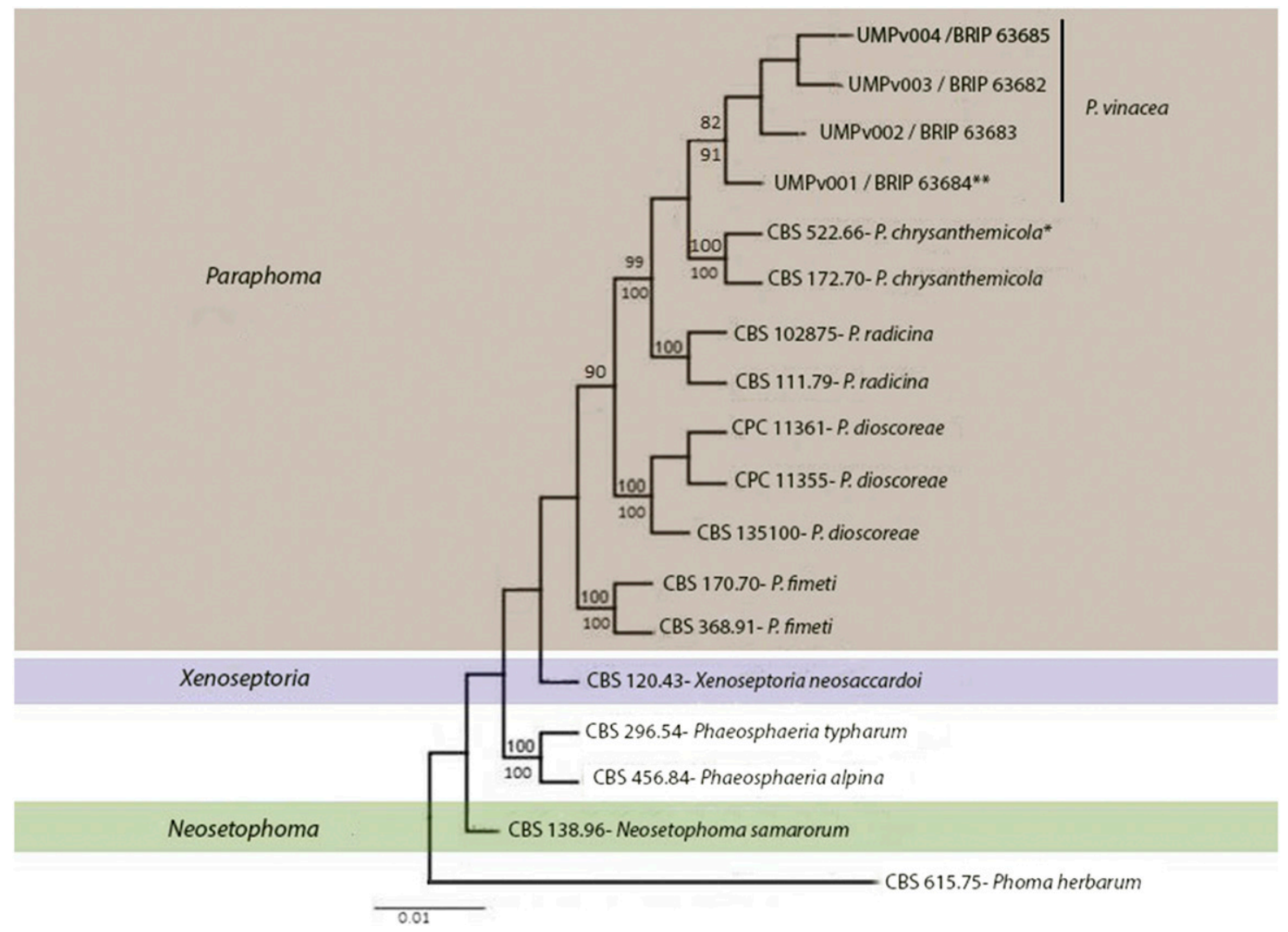

Fig. 2. Maximum-likelihood combined phylogenetic tree of internal transcribed spacer/large subunit using the $\mathrm{K} 2+\mathrm{G}+\mathrm{I}$ substitution model. Highest log likelihood $-3,270.3597$. The analysis involved 18 nucleotide sequences. Maximum-likelihood bootstrap values were shown above nodes and neighbor-joining values under nodes. The tree was rooted to Phoma herbarum CBS 615.75. Bootstrap values less than $70 \%$ were deleted; * refers to the ex-neotype of Paraphoma chrysanthemicola and ${ }^{* *}$ refers to the ex-holotype of $P$. vinacea. Scale bar indicates expected changes per site. 
experiment, $P$. vinacea significantly reduced belowground and total biomass of the root-dip-inoculated pyrethrum plants but had no effect on aboveground biomass (Table 2).

\section{Discussion}

$P$. vinacea was isolated mainly from the crown and upper primary root tissues of pyrethrum plants affected by crown rot disease in yield-decline sites of Tasmania. The four isolates which were considered in the phylogenetic study were representative of all the other isolates recovered from different tissues of infected plants. $P$. vinacea significantly reduced plant growth, especially of the belowground biomass within 2 months after inoculation in two glasshouse bioassays. The difference in severity of infection between the two bioassays may have been due to the size of the plants and growing conditions. Experiment 1 involved inoculation of 2-month-old plants (compared with 3-month-old plants in experiment 2) and was planted in winter, where the shorter day length may have slowed plant growth. Slow plant growth may have affected the severity of infection in these plants over the 2-month growing period and resulted in only significant belowground biomass reduction, compared with significant reduction in both belowground and total plant biomass in experiment 1 .

The inoculation method selected to reproduce Paraphoma crown rot disease and determine the effect on plant growth involved dipping the roots in spore suspension followed by transferring plants to soil in pots. Although the number of infected plants in root dip and soil drench methods was equal (75\%), the root dip technique was selected to be used in all experiments because an equal volume of inoculum (spore suspension) could be consistently delivered to the roots of the plants.
In the foliar spraying inoculation method, crown discoloration and tissue necrosis only occurred in $50 \%$ of the infected plants. Infection may have occurred by the run-off of spores after inoculation down the petiole to the crown region which subsequently resulted in infection of the crown tissue. However, the run-off probably contained a low concentration of spores; hence, the infection pressure was low, resulting in reduced incidence and severity of infection.

$P$. vinacea, a new species causing crown rot disease of pyrethrum in Australia, was described based on morphological characteristics,

Table 2. Effect of Paraphoma vinacea on aboveground, belowground, and total dry weight of pyrethrum plants inoculated by root dip method comparing the least significant difference of the means (LSD) ${ }^{\mathrm{x}}$

\begin{tabular}{|c|c|c|c|c|c|c|}
\hline \multirow[b]{2}{*}{ Experiments } & \multirow[b]{2}{*}{$N^{\mathbf{y}}$} & \multicolumn{2}{|c|}{ Dry weight (g) } & \multirow[b]{2}{*}{ LSD } & \multirow[b]{2}{*}{$\mathbf{S E}^{\mathbf{z}}$} & \multirow[b]{2}{*}{$P$ value } \\
\hline & & Control & $\begin{array}{l}P . \text { vinacea } \\
\text { inoculation }\end{array}$ & & & \\
\hline \multicolumn{7}{|l|}{$\overline{\operatorname{Exp} 1}$} \\
\hline Aboveground & 8 & $2.78 \mathrm{a}$ & $2.83 \mathrm{a}$ & 0.84 & 2.81 & 0.93 \\
\hline Belowground & 8 & $1.69 \mathrm{a}$ & $0.79 \mathrm{~b}$ & 0.59 & 1.27 & 0.006 \\
\hline Total & 8 & $4.84 \mathrm{a}$ & $3.63 \mathrm{a}$ & 1.12 & 4.08 & 0.12 \\
\hline \multicolumn{7}{|l|}{ Exp 2} \\
\hline Aboveground & 10 & $10.48 \mathrm{a}$ & $8.21 \mathrm{a}$ & 2.97 & 9.04 & 0.12 \\
\hline Belowground & 10 & $6.64 \mathrm{a}$ & $4.59 \mathrm{~b}$ & 1.23 & 5.61 & 0.002 \\
\hline Total & 10 & $17.12 \mathrm{a}$ & $12.81 \mathrm{~b}$ & 4.02 & 14.96 & 0.03 \\
\hline
\end{tabular}

${ }^{\mathrm{x}}$ Significant means shown in bold type. Means with different letters are significantly different.

y Number of plants used.

${ }^{\mathrm{z}}$ Standard error of the mean

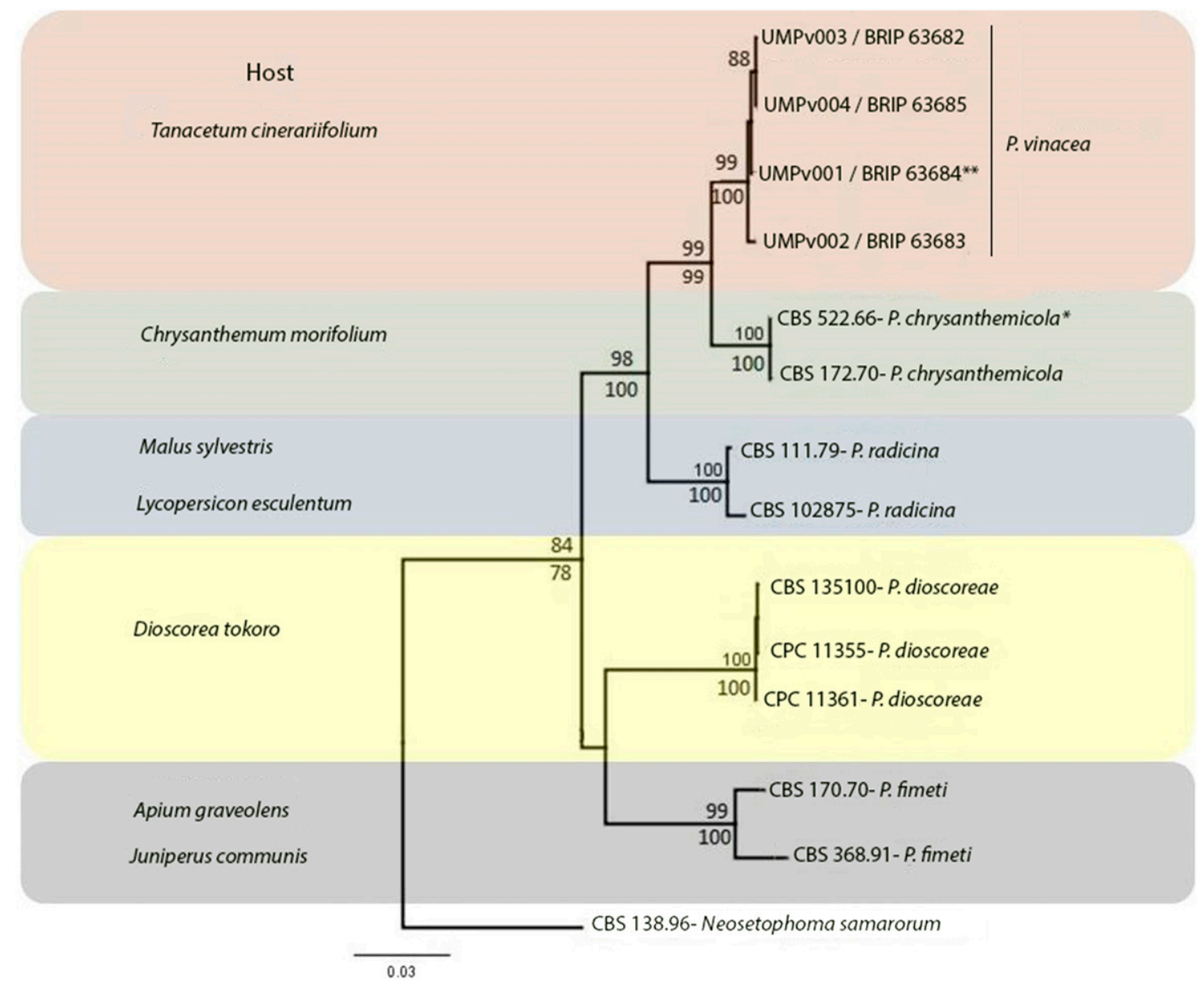

Fig. 3. Maximum-likelihood combined phylogenetic tree of internal transcribed spacer/elongation factor $1-\alpha / \beta$-tubulin using the K2+I substitution model. Highest log likelihood $-2,886.23$. The analysis involved 14 nucleotide sequences. Maximum-likelihood bootstrap values were shown above nodes and neighbor-joining values under nodes. The tree was rooted to Neosetophoma samarorum CBS 138.96 . Bootstrap values less than $70 \%$ were deleted; * refers to the ex-neotype of Paraphoma chrysanthemicola and ** refers to the ex-holotype of $P$. vinacea. Scale bar indicates expected changes per site. 
multigene phylogenetic analyses, and pathogenicity assays. Phylogenetic analyses based on different gene combinations (LSU/ITS, ITS/ tefl/TUB, or ITS/TUB/ACT) clearly distinguished $P$. vinacea from the closely related $P$. chrysanthemicola. Furthermore, tefl appeared to be more informative than $T U B$, because the bootstrap support and number of informative sites in the individual tefl tree was more than that in the TUB tree.

Morphological differences such as spore size also clearly distinguished $P$. vinacea from $P$. chrysanthemicola. The spore size of $P$. chrysanthemicola was slightly shorter (spore dimension on OA of 4 to 6 by 1.5 to $2.5 \mu \mathrm{m}$ ) (Johnston 1981) than for $P$. vinacea. However, other micromorphological characteristics such as the production of aggregated chlamydospores, pillose, or semipillose pycnidia (Boerema et al. 2004) were similar for the two species. Morphological differences along with molecular DNA data enabled $P$. vinacea to be reassessed as a new species in Paraphoma.

$P$. chrysanthemicola was reported as a minor pathogen of pyrethrum plants in the fields of Tasmania associated with foliar lesions and was isolated at low frequency (26\%), (Hay et al. 2015). Further research is required to determine the relationship between $P$. chrysanthemicola and $P$. vinacea in pyrethrum and to determine if, indeed, both pathogens occur on this crop. Moreover, the association of $P$. vinacea with pyrethrum yield decline across Tasmania and Victoria and the role of abiotic stresses in increasing the severity of Paraphoma crown rot disease need to be further investigated.

\section{Acknowledgments}

We thank the University of Melbourne for a Melbourne International Research Scholarship which supported this study and Botanical Resources AustraliaAgricultural Services Pty. Ltd. for providing pyrethrum seedlings and supplementary funding for this project.

\section{Literature Cited}

Aveskamp, M. M., De Gruyster, J., and Crous, P. W. 2008. Biology and recent developments in the systematics of Phoma, a complex genus of major quarantine significance. Fungal Divers. 31:1-18.

Aveskamp, M. M., de Gruyter, J., Woudenberg, J. H., Verkley, G. J., and Crous, P. W. 2010. Highlights of the Didymellaceae: A polyphasic approach to characterise Phoma and related pleosporalean genera. Stud. Mycol. 65:1-60.

Aveskamp, M. M., Verkley, G. J., de Gruyter, J., Murace, M. A., Perello, A., Woudenberg, J. H., and Crous, P. W. 2009. DNA phylogeny reveals polyphyly of Phoma section Peyronellaea and multiple taxonomic novelties. Mycologia 101:363-382.

Barimani, M., Pethybridge, S. J., Vaghefi, N., Hay, F. S., and Taylor, P. W. J. 2013. A new anthracnose disease of pyrethrum caused by Colletotrichum tanaceti $\mathrm{sp}$. nov. Plant Pathol. 62:1248-1257.

Boerema, G. H., de Gruyter, J., Noordeloos, M. E., and Hamers, M. E. C., eds. 2004. Phoma Identification Manual. Differentiation of Specific and InfraSpecific Taxa in Culture. CABI Publishing, Wallingford, Oxfordshire, UK and Cambridge, MA.

Carbone, I., and Kohn, L. M. 1999. A method for designing primer sets for speciation studies in filamentous ascomycetes. Mycologia 91:553-556.

Crous, P. W., Verkley, G. J. M., Groenewald, J. Z., and Samson, R. A., eds. 2009. Fungal Biodiversity. CBS Laboratory Manual Series 1. CBS-KNAW Fungal Biodiversity Centre, Utrecht, The Netherlands.

de Gruyter, J., and Boerema, G. H. 2002. Contributions towards a monograph of Phoma (Coelomycetes) VIII-Section Paraphoma: Taxa with setose pycnidia. Persoonia 17:541-561.

de Gruyter, J., van Gent-Pelzer, M. P. E., Woudenberg, J. H. C., van Rijswick, P. C. J., Meekes, E. T. M., Crous, P. W., and Bonants, P. J. M. 2012. The development of a validated real-time (TaqMan) PCR for detection of Stagonosporopsis andigena and S. crystalliniformis in infected leaves of potato and tomato. Eur. J. Plant Pathol. 134:301-313.

de Gruyter, J., Woudenberg, J. H. C., Aveskamp, M. M., Verkley, G. J. M., Groenewald, J. Z., and Crous, P. W. 2010. Systematic reappraisal of species in Phoma section Paraphoma, Pyrenochaeta and Pleurophoma. Mycologia 102:1066-1081.

de Hoog, G. S., and Gerrits van den Ende, G. H. 1998. Molecular diagnostics of clinical strains of filamentous Basidiomycetes. Mycoses 41:183-189.

Dorenbosch, M. J. 1970. Key to nine ubiquitous soil-borne Phoma-like fungi. Persoonia 6:1-14.

Garibaldi, A., and Gullino, M. 1. 1981. Root rot of chrysanthemum caused by Phoma chrysanthemicola Hollos f. sp. chrysanthemicola Schn. et Boerema in Italy. Inf. Fitopatol. 31:27-23.

Hammond, K. E., and Lewis, B. G. 1987. The establishment of systemic infection in leaves of oilseed rape by Leptosphaeria maculans. Plant Pathol. 36:135-147.

Hay, F., Gent, D. H., Pilkington, S., Pearce, T. L., Scott, J. B., and Pethybridge, S. J. 2015. Changes in distribution and frequency of fungi associated with foliar diseases complex of pyrethrum in Australia. Plant Dis. 99:1227-1235.

Hay, F. S., Stirling, G., Chung, B., and Groom, T. 2002. Investigation into the Cause of Pyrethrum Regrowth Decline (RPD) with Emphasis on the Role of Plant-Parasitic Nematodes. Horticulture Australia, Sydney, NSW, Australia.

Johnston, P. R. 1981. Phoma on New-Zealand grasses and pasture legumes. N.Z. J. Bot. 19:173-186.

Kearse, M., Moir, R., Wilson, A., Stones-Havas, S., Cheung, M., Sturrock, S., Buxton, S., Cooper, A., Markowitz, S., Duran, C., Thierer, T., Ashton, B., Mentjies, P., and Drummond, A. 2012. Geneious Basic: An integrated and extendable desktop software platform for the organization and analysis of sequence data. Bioinformatics 28:1647-1649.

O’Donnell, K., Kistler, H. C., Cigelnik, E., and Ploetz, R. 1998. Multiple evolutionary origins of the fungus causing Panama disease of banana: Concordant evidence from nuclear and mitochondrial gene genealogies. Appl. Biol. Sci. 97: 2044-2049.

Pearce, T. L., Scott, J. B., Crous, P. W., Pethybridge, S. J., and Hay, F. S. 2016. Tan spot of pyrethrum is caused by a Didymella species complex. Plant Pathol. 65:1170-1184.

Pethybridge, S. J., Hay, F. S., Esker, P. D., Gent, D. H., Wilson, C. R., Groom, T., and Nutter, F. W. 2008. Diseases of pyrethrum in Tasmania: Challenges and prospects for management. Plant Dis. 92:1260-1272.

Quaedvlieg, W., Verkley, G. J. M., Shin, H. D., Barreto, R. W., Alfenas, A. C., Swart, W. J., and Crous, P. W. 2013. Sizing up Septoria. Stud. Mycol. 75:307-390.

Rayner, R. W., and British Mycological Society. 1970. A Mycological Colour Chart. Commonwealth Mycological Institute, Kew, Surrey, UK.

Rehner, S., and Samuel, G. J. 1994. Taxonomy and phylogeny of Gliocladium analysed from nuclear large subunit ribosomal DNA sequences. Mycol. Res. 98:625-634.

Roustaee, A., Dechamp-Guillaume, G., Gelie, B., Savy, C., Dargent, R., and Barrault, G. 2000. Ultrastructural studies of the mode of penetration by Phoma macdonaldii in sunflower seedlings. Am. J. Phytopathol. 90:915-920.

Srivastava, S. N. S. 1953. On the occurrence of Phoma chrysanthemicola Hollos on Chrysanthemum sp. Curr. Sci. 22:216.

Tamura, K., Stecher, G., Peterson, D., Filipski, A., and Kumar, S. 2013. MEGA6: Molecular evolutionary genetics analysis version 6.0. Mol. Biol. Evol. 30: 2725-2729.

Vaghefi, N., Pethybridge, S. J., Ford, R., Nicolas, M. E., Corus, P. W., and Taylor, P. W. J. 2012. Stagonosporopsis spp. associated with ray blight disease of Asteraceae. Australas. Plant Pathol. 41:675-686.

Vilgalys, R., and Hester, M. 1990. Rapid genetic identification and mapping of enzymatically amplified ribosomal DNA from several cryptococcus species. Bacteriology 172:4238-4246.

White, T. J., Bruns, T., Lee, S., and Taylor, J. 1990. Amplification and direct sequencing of fungal ribosomal RNA genes for phylogenetics. Pages 315-322 in: PCR Protocols: A Guide to Methods and Applications. M. A. Innis, D. H. Gelfand, J. J. Sninsky, and T. J. White, eds. Academic Press, San Diego, CA.

Woudenberg, J. H. C., Aveskamp, M. M., de Gruyter, J., Spiers, A. G., and Crous, P. W. 2009. Multiple Didymella teleomorphs are linked to the Phoma clematidina morphotype. Persoonia 22:56-62. 